\title{
Familiarity with Collocations in EFL Context and Strategies Utilized in Translating Them into Arabic
}

\author{
Hussein Ali Habtoor \\ Dept. of English, Aden University, Yemen \\ Raisah Hamad Al-Swaidan \\ Dept. of English, Najran University, KSA
}

\begin{abstract}
This paper aims at examining the familiarity of English as a Foreign Language (EFL) learners at Najran University with English collocations and the strategies being used when translating them into Arabic. The data of this study are collected from 40 female EFL learners of the English Department at Najran University. The participants' familiarity with English collocations is measured by means of a two-part test adopted from Gyllstad (2007). A translation test consisting of 48 collocations in both short texts and short sentences has been used to determine the participants' familiarity with translation strategies when translating English collocations into Arabic. Results show that Najran University EFL learners' knowledge of collocations is unsatisfactory and below what is expected from them as English language major students. The results of the Pearson correlation test indicate a positive relationship between the learners' familiarity with English collocations and their ability to translate them into Arabic using different translation strategies.
\end{abstract}

Index Terms-collocations, translation strategies, translation problems, familiarity with collocations, vocabulary acquisition

\section{INTRODUCTION}

For a long time, the importance of vocabulary acquisition has been neglected and deemed secondary, and learning the vocabulary of a new language has been considered to happen spontaneously. The low priority given to vocabulary learning stems from long-established language teaching approaches that focus on grammar and phonology. Only in the late 20th century did the teaching of vocabulary gain recognition, and many scholars and language teaching approaches have emphasized teaching vocabulary (Koç 2006). Wilkins (1972) asserts that '[without] grammar very little can be conveyed; without vocabulary nothing can be conveyed' (p. 111). At the beginning, vocabulary teaching merely focused on memorising long lists of bilingual words in isolation. However, this approach has been proven ineffective when employing vocabulary in communicative situations (Alsakran 2011).

Collocation is a subcategory of word combination. Oxford Collocations Dictionary (2002) defines collocation as 'the way words combine in a language to produce natural-sounding speech and writing' (p.7). McCarthy (1990) asserts that collocation is 'an important organising principle in the vocabulary of any language' (p.12). The knowledge of collocations is vital and is regarded as a requisite for translators. To render natural and comprehensible texts in the target language that convey the spirit and essence of source language texts, the translator should have a good command of collocations. Still, translating collocations is a major challenge even for the most professional translators (Baker, 1992, Brashi, 2005, Dewik and Abu Shakra, 2011). Hatim and Mason(1990) note the 'danger that, even for experienced translators, source language interference will occasionally escape unnoticed and an unnatural collocation will flaw the target text' (p. 204).

The difficulty of collocations can be attributed to its arbitrary nature; that is, no hard and fast rule exists in deciding how words collocate with each other (Farrokh 2012). Zughoul (1991) asserts that 'different languages have different collocation modes; what collocates in one language does not necessarily collocate in another language' (p.5). More emphasis is still placed on single words rather than collocations in compiling dictionaries and learning languages (Koç, 2006). Husni and Newman (2015) note that '[an] Arabic English translator was, until relatively recently, hampered by the dearth of dedicated lexicographical tools as general dictionaries are often not of great help' (p.15). Moreover, the learners' knowledge of collocations is generally observed to be far behind their knowledge of single vocabulary items because the kind of instruction they receive focuses on learning isolated vocabulary items (Farghal \& Obiedat, 1995; Huang, 2001; Nesselhauf, 2003; Zughoul \& Abdul-Fattah, 2003).

\section{A. Statement of the Problem}

Despite its undeniable importance, collocations are underestimated by teachers, EFL individual learners or those who are responsible for language learning planning. Vocabulary acquisition in language learning is still mainly focused on 
isolated words, whereas the learning of collocations is left to chance or to the individual efforts of learners and teachers. As a result, learners continue to have difficulty with comprehension or production of collocations. Similarly, translating collocations represents a huge challenge for students and professional translators. Thus, they tend to use some strategies when trying to overcome the difficulties in translating collocations. The learners' awareness of English collocations and the strategies employed when translating them into Arabic have to be identified. If a correlation exists between the learners' familiarity with collocations and translation strategies, then it is important to allocate.

\section{B. Purpose of the Study}

Many EFL learners face difficulty in comprehending and producing collocations because of inefficient teaching and the inherent properties of collocations. Similarly, translating collocations is a challenging task for many students, who have to use various translation strategies when hampered by these difficulties. This study aims to find if a relationship exists between EFL learners' familiarity with collocations and their awareness of translation strategies. In addition, this study attempts to shed light on some of the causes of students' difficulty when translating collocations. It tries to answer the following questions:

1. To what extent are Najran University EFL learners familiar with English collocations?

2. To what extent are Najran University EFL learners familiar with translation strategies in rendering English collocations into Arabic?

3. Is there a relationship between Najran University EFL learners' familiarity with English collocations and the strategies they use to translate these collocations into Arabic?

4. What are the most common reasons behind the students' difficulties when translating collocations?

\section{RIVERVIEW OF LITERATURE}

\section{A. The Importance of Collocations}

Under the heading of 'The Beautiful Language of Collocation', Gazalah (2007) notes that collocations are 'the source of [the language's beauty in the sense of being aesthetic, expressive, effective and hence rhetorical. After all, collocations are in the heart of rhetoric'(p.19). He asserts that the incorporation of collocations leads to a more beautiful, colourful and expressive language. He clarifies his point by listing examples of some collocations and their counterpart ordinary words (p. 20). Collocations constitute an important part of any language and the collocational knowledge is an indispensable requirement for learning a language. Collocations comprise "up to $70 \%$ of everything we say, hear, read or write' (Hill, 2000, p.53). Therefore, collocations deserve more attention when teaching a language. Language is acquired and produced in chunks rather than in individual words. The vocabulary repertoire of the native speaker consists of a large number of ready-made chunks that facilitate the communication process and save the effort of using long phrases. Therefore, the knowledge of collocations helps develop not only the linguistic lexicon but also the ability to communicate naturally and effortlessly. As stated by Lewis (1997), 'fluency is based on the acquisition of a large store of fixed and semi-fixed prefabricated items' (p.15).

Regardless of the fact that collocation plays a vital role in the receptive and productive skills of a language and helps to improve the overall communicative ability, it has been neglected for a long time when teaching vocabulary, and the focus has been on isolated words rather than ready-made chunks used by native speakers in oral or written communication.

\section{B. Problems in Translating Collocations}

As mentioned, collocations can be regarded as a standard for judging the naturalness of a text. Consequently, being able to translate collocations and obtaining the most appropriate equivalent is crucial for any translator. Collocation is a fascinating aspect of languages and an indication of the competence of translators. Translating collocations is not an easy task because it requires a high degree of skills and knowledge on the part of the translator given that finding accurate collocational equivalents across languages is almost impossible. Thus, translating collocations imposes a huge challenge on translators even the most experienced ones. In this respect, Newmark (1988)notes:

Translation is sometimes a continual struggle to find appropriate collocations, a process of connecting appropriate nouns with verbs and verbs with nouns, and, in the second instance, collocating appropriate adjectives to the nouns, and adverbs or adverbial groups to the verbs; in the third instance, collocating appropriate connectives or conjunctions. (p.213)

One of the factors to which the difficulty of translating collocations can be attributed is the arbitrary nature of collocations where the meaning of collocations cannot be predicted using syntactic or semantic rules, or what Rabeh (2009, p.31) refers to as 'the difficulty of generalisation'. For example, some English words collocate with one and the same words, but the Arabic equivalent of these words do not necessarily collocate with the same words in Arabic.

In addition, Rabeh (2009) asserts that the 'variability' of collocations adds to the difficulty of learning and translating collocations by EFL learners. That is, different collocations can denote the same meaning in English, but only a single collocation is used to convey the same meaning in Arabic and vice versa.

The large number of collocations in English is one of the important factors behind the problems of collocations. Many studies indicate that the number of collocations in English is by far much larger than the number of vocabulary 
items. 'The BBI Combinatory Dictionary of English offers more than 70,000 combinations and phrases under a total of 14,000 entries and Collins COBUILD English Words in Use provides approximately 100,000 collocational examples which are grouped around 5,000 headwords from the core vocabulary of modern English' (Bahns, 1993, p. 59). Consequently, this factor imposes difficulty when it comes to deciding which collocations to focus on in teaching.

The effect of learners' mother tongue ' $1 \mathrm{~L}$ transfer' is amongst the most prominent factors to which the problematicity of collocations can be attributed. Many previous studies which aim to figure out the sources of collocational errors made by EFL learners have found that most of these errors are due to students' reliance on their mother tongue (Nesselhauf, 2003;Zughoul \& Abdul-Fattah, 2003;Brashi 2005). When students are unsure of a correct collocation used in the target language, they resort to their first language to compromise this linguistic deficiency, and the result is mostly odd and unnatural because of the arbitrary nature of collocations and how they widely vary across different languages.

Furthermore, the negligence of collocations in second and foreign language teaching and learning is another factor behind the problematicity of collocations. Nation (2001, p.33) asserts that knowing a word entails incorporating three categories: meaning, form and use. The knowledge of a word's form refers to the knowledge of its written and spoken forms. The knowledge of meaning calls for the incorporation of a number of constituents including references, connotative meaning and sense relations. The use category covers the knowledge of the 'collocational behaviour of the word' and the stylistic and grammatical constraints on the use of the word in a given linguistic context. The last category, 'the use of word'has received the least attention in contexts of teaching and learning vocabulary because of a general tendency to focus on words in isolation without considering their neighbourhood and how they are used in chunks.

\section{Translation Strategies}

Translation is not an easy task as a translator faces various problems in the process. To solve these problems, the translator uses certain strategies. Hence, translation strategies can be defined as 'procedures which the subjects employ in order to solve translation problems' (Lörscher, 2005,p.76-81).

Various taxonomies and classifications of translation strategies have been proposed by different scholars depending on their perspectives of translation. Newmark (1988) argued that 'when the translator is involved in the process of translation, he is always trying to solve a thousand small problems in the context of a large one' (p.8). Thus, Newmark (1988)offered a number of strategies(p.45-46) to help translators deal with problems:1.Word-for-word translation 2.Literaltranslation 3.Faithful translation 4.Semantic translation 5.Adaptation 6.Free translation 7.Idiomatic translation 8.Communicative translation. Baker (1992) regarded translation strategies as ways to handle 'various types of non-equivalence' (p.26). She suggested eight strategies used by professional translators to deal with translation problems:1. Translation by a more general word. 2.Translation by a more neutral/less expressive word 3.Translation by cultural substitution 4. Translation using a loan word or a loan word with an explanation 5. Translation by paraphrase using a related word 6. Translation by paraphrase using unrelated words.7. Translation by omission.8. Translation by illustration. The linear set of translation strategies suggested by Vinay and Darbelnet (1995) is one of the most comprehensive taxonomies that can be applied to most translation actions and also one of the most quoted taxonomies of translation solutions. Vinay and Darbelnet (1995) proposed two general translation methods or strategies: 1 . Direct or literal translation. 2. Indirect or oblique translation. The two main strategies are broken down into the following seven subcategories (Vinay \& Darbelnet 1995, p.31-39):

1. Direct or literal translation which consists of: 1. Borrowing 2. Calque 3. Literal translation.

2. Indirec or oblique translation which consists of: 1. Transposition 2. Modulation 3. Equivalence 4. Adaptation.

\section{Empirical Studies}

Collocations have been receiving close attention in the last two decades. Many studies have dealt with different issues related to collocations in the EFL context. Although some studies have focused on the acquisition, learning and production of collocations, others have spotlighted collocations from the viewpoint of translation.

Zughoul and Abdul-Fattah (2003) investigated the proficiency level of translating English collocations into Arabic by Arab-speaking EFL learners and the strategies employed in translation. The results indicated that the overall performance of the subjects in the target collocations is far from satisfactory. A total of 12 distinct communicative strategies were also identified and characterised as avoidance, literal translation, substitution, overgeneralisation, quasimetaphorical similarity, assumed synonymity, derivativeness, imitation of literary style, idiomaticalness, paraphrase and circumlocution, graphic ambiguity and false TL assumption.

Al-Sakran (2011) investigated the productive and receptive knowledge of lexical and grammatical collocations amongst advanced Arabic-speaking learners of English. He also explored the effect of learning environment (whether EFL or ESL) on the acquisition of collocations. The study showed that the ESL learners performed much better than the EFL learners, which indicated that the learning environment had a strong effect on the performance of learners. Generally, the study reveals that the collocational knowledge of Arab-speaking learners of English is unsatisfactory and has made pedagogical suggestions to improve learners' performance in this important aspect of language.

Noor and Adubaib (2011) conducted a study to determine the strategies which Saudi EFL learners employ in producing collocations. Thirty students of Taibah University were given two tests: fill-in-the blank test accompanied by 
a self-checklist and a translation test. Additionally, interviews were conducted with the participants to learn about the strategies they used in the given tasks. The analysis of the collected data indicated that the students produced unacceptable collocations more frequently than the accepted ones. The study also showed that the participants employed L2-based strategies more often than other strategies in producing acceptable and unacceptable collocations. The order of the strategies which participants used in producing collocations was as follows: firstly, L2-based strategies; secondly, L1-based strategies; thirdly, reduction strategies and lastly, test-taking strategies (p.589).

Shammas (2013) attempted to assess the comprehension and production of collocation of Master of Arts (MA) students from four Arab universities. The results of the study showed that the overall performance of the students were unsatisfactory and below what was expected from MA students. The four factors influencing students' weakness in comprehension and use of collocations were identified as follows:

'1. Lack of knowledge of the collocations in question; 2. Shortage or even scarcity of Arabic-English or EnglishArabic collocation dictionaries; 3. Lack of consciousness of the role of collocation in expressing 'meaning' as intended in context; 4. Lack of concentration on collocation in EFL or translation classes at Arab universities or schools' (p.15).

Abdullah (2014) investigated the knowledge of English collocations amongst Sudanese English majors and attempted to identify the causes of collocational errors. The results show a low level of collocational knowledge amongst the Sudanese learners. The inadequate knowledge was attributed to 'lexical overgeneralization and negative interlingual transfer from the mother tongue'.

Hadi (2014) conducted a study to investigate Iraqi EFL learners' use of English lexical collocations. The results of this study showed that the participants' overall performance was 'disappointing' because of linguistic incompetence. To overcome this obstacle, the students made use of three translation strategies: literal transfer, generalisation and transfer. Jabak, Abdullah and Mustafa (2016) examined the difficulties faced by undergraduate Saudi learners when translating collocations and identified the reasons. Findings of the study showed that the difficulties when dealing with collocations could be attributed to the following: 1) students' heavy reliance on literal translation, 2) use of bilingual dictionaries only, and 3) deficiency in knowledge of collocations in both the Arabic and English languages.

Many studies investigated the knowledge of collocations of Arabic-speaking EFL learners from different levels and proved that English collocations were a serious problem for most of them. Other studies focused on the strategies that students could use when translating English collocations into Arabic. The present study attempts to determine Najran University EFL learners' familiarity with English collocations and also with the strategies employed when translating English collocations into Arabic. Moreover, this study aims to investigate a possible correlation between the learners' familiarity with English collocations and the strategies they use when translating collocations into Arabic. Furthermore, this study attempts to understand the underlying process of producing collocations that learners employ to compensate for their deficient knowledge, and whether their knowledge is reflected on their ability to translate collocations.

\section{Methodology}

\section{A. Participants}

The participants in this study are 40 EFL Saudi female students chosen randomly from Level 6 of the English Department of Najran University. The mean age of the participants was 22. All of the participants are native speakers of Arabic, and none of them has lived in an English-speaking environment previously. They have passed the Translation 1 course and are currently attending the Translation 2 course. These selection criteria establish that the participants have a good command of English and are aware of the translation process and its strategies.

\section{B. Instruments}

For this study, three data collection methods are used: a diagnostic test, a translation test and a questionnaire. The diagnostic test is used to identify the students' proficiency level in English collocations to determine how familiar they are with this linguistic aspect. The translation test is conducted to examine the strategies employed by students when translating collocations from English into Arabic and to determine the correlation between the participants' knowledge of English collocations and the strategies they use to translate them into Arabic. The questionnaire identifies some of the common reasons behind the students' difficulties in translating collocations.

\section{Collocation Test (COLLEX and COLLMATCH)}

The collocation test, a two-part test with a total mark of 50 points, is intended to elicit students' perception and familiarity with collocations. These two parts are adapted from Gyllstad's (2007) collocating lexis (COLLEX) and collocate matching (COLLMATCH), respectively. The first part only includes 25 multiple choice questions out of the 40 original items from COLLEX. Each test item contains three word-combination options, where one of the options is a natural and frequently occurring combination in the English language and the other two items are not. Students are asked to choose the answers that they think are the most natural and frequently occurring in English. Each correct answer is equivalent to one point and the test has a total score of 25 points. The second part only uses 10 out of 20 items from COLLMATCH. Each item comprises of five English word sequences. The five-word sequence includes common English word combinations and word combinations that do not occur naturally in English. The students are asked to choose the English sequences which are natural and frequently used. Each correct sequence is given half a point. The students are given points for ticking the correct sequences and for leaving or crossing out the incorrect sequences, and 
all the wrong choices or blank answers are given zero point. The total points in this part are25. The number of correct and frequent combinations in this part is 34 while the number of incorrect ones is 16 . A total of 59 collocations are employed in this two-part test and the English level of the students (advanced and upper intermediate levels) are considered when choosing the items for these two parts.

2. Questionnaire

A two-part questionnaire was used to obtain the reasons for the students' difficulties in translating collocations and used a 5-point Likert scale ranging from 1 (strongly agree) to 5 (strongly disagree). The first part included six items on the students' background knowledge of translation and collocations. The second part included eight items on some of the most common sources of difficulties in translating collocations.

3. Translation Test

A two-parts translation test was used in this study. The aim of this test was to investigate the strategies employed by the students when translating collocations from English into Arabic. In the first part, the students were asked to select one of three given texts in which a number of common collocations were used and translate the selected text from English into Arabic. All three texts were taken from the book English Collocations in Use: Advanced by O'Dell, and McCarthy, (2008), Cambridge University Press. The second part includes10 relatively short English sentences containing common collocations to be translated into Arabic. In constructing the two parts of the test, the level of students was considered and all collocations in the test were commonly used and relatively easy and suitable to the participants' level (upper-intermediate or advanced learners) of English; thus, the students would not experience difficulty in understanding the meaning of the given texts.

\section{Procedures}

\section{Administering the Collocation Test}

The collocation test was distributed amongst 40 EFL learners chosen randomly from 58 sixth-level students. Aside from the written instructions, additional explanations on the idea of collocation and examples of English and Arabic collocations were given to the students to establish that all of them had a clear idea of the concept in question. Furthermore, the students were given clear instructions on the purpose of the test and the confidentiality of the given personal information.

2. Administering the Questionnaire

The questionnaires were distributed to the same participants who had taken the collocation test. They were given instructions on the purpose of the study. Explanations in English and Arabic were provided for those students who had sought clarification on some items.

3. Administering the Translation Test

After ensuring that all the items were comprehensible and appropriate to the participants' level, the translation test was distributed to the same students. The participants were asked to perform the translation task without consulting dictionaries or any other materials because the purpose of the test was to determine the participants' actual familiarity with collocations without resorting to any resources. Use of dictionaries in the translation test might lead some students to depend on finding synonyms, thereby preventing them from employing different translation strategies.

\section{RESULtS}

This section describes the analysis of the collected data from the different tools applied in this study using descriptive and inferential statistics. The collected data are analysed using SPSS. Percentage of the used strategies in the translation test as well as the frequencies, means and percentage of the participants' responses in the questionnaire are calculated. For inferential statistics, Pearson correlation test is employed to determine the relationship between learners' knowledge of collocations and their awareness of translation strategies when rendering English collocations into Arabic. One sample t-test is employed to investigate the learners' familiarity with English collocations and with translation strategies when rendering collocations from English to Arabic.

\section{A. Learners' Familiarity with Collocations and Their Translation Strategies}

To answer the first question 'To what extent are Najran University EFL learners familiar with English collocations?', we conducted a descriptive analysis of the collocation test. In this analysis, we examined the difference between the assumed test value $=5$ and the mean of the students' scores in the collocation test using one sample t-test. The results are shown in Table1.

TABLE I.

RESUlTS Of ONE SAMPLE T-TEST OF ENGLISH COLLOCATION KNOWLEDGE
\begin{tabular}{|l|l|l|l|l|l|l|l|}
\hline & $\mathrm{N}$ & Mean & SD & Std. Error Mean & t-test & df & sig \\
\hline Collocations test & 40 & 21.36 & 5.63 & 0.89 & 18.37 & 39 & 0.65 \\
\hline
\end{tabular}

Table 1 shows that the mean score of the sample in the collocation test is 21.36 with a standard deviation score of 5.63 and no significant difference exists between the mean degree of the students in the collocation test and our supposed mean $=5$ (where $\mathrm{t}$-value $=18.3, p>0.05)$. 
One sample t-test of the participants' scores in the translation test was used to investigate the extent to which the EFL learners were familiar with the translation strategies in rendering English collocations into Arabic. The difference between the assumed test value (5) and the mean of the participants' scores was examined. Results are presented in table 2 .

TABLE II.

RESUlts Of ONE SAMPLE T-Test OF ENGLish TRANSLATION STRATEGIES

\begin{tabular}{|l|l|l|l|l|l|l|l|}
\hline & $\mathrm{N}$ & Mean & SD & Std. Error Mean & t-test & df & sig \\
\hline Translation test & 40 & 10.96 & 3.18 & 0.50 & 11.83 & 39 & 0.55 \\
\hline
\end{tabular}

Table 2 shows that the mean score of the sample in the translation test is 10.96 with a standard deviation score $=$ 3.18. No significant difference exists between the mean degree of the students' scores in the translation test and our supposed mean of $5(\mathrm{t}$-value $=11.83, \mathrm{p}>0.05)$.

\section{B. Translation Strategies Employed by Learners in Rendering Collocations into Arabic}

As previously mentioned, the results of the one sample t-test for the students' marks, which are obtained in the translation test, indicate that they face difficulty when translating English collocations into Arabic and the level of their awareness of translation strategies for translating collocations is unsatisfactory. The following section focuses on the analysis of the used strategies in the responses given by the students.

The translation test consists of two parts. The first part comprises of three texts in which the targeted collocations are written in boldface letters and the participants are asked to translate any one of these texts. Amongst the study participants, 16 students decided to translate the first text, 11 chose the second and 13translated the third one. Thus, the frequency of translation strategies used by the students in translating collocations are presented separately for each text and the average of the frequencies of the translation strategies used in the three texts is calculated. The second part consists of 10 sentences and each sentence contains a common collocation written in boldface letters. The frequencies of the translation strategies used in these sentences are calculated and the average of the percentages of the used translation strategies in both parts of the test is calculated to achieve the translation strategies employed when rendering collocations from English into Arabic.

1. First: The First Part of the Test: Translating Texts

a. Translation Strategies Used in the First Text.

Table 3 shows that synonyms are the most frequently used strategy for translating collocations into Arabic with a rate of $20.9 \%$, followed by literal translation with a rate of $18.03 \%$. The strategy of deletion accounted for $11.7 \%$. Paraphrasing and elaboration are the least frequently used strategies with rates of $3.28 \%$ and $4.5 \%$, respectively.

TABLE III.

Frequency And Total Percentage Of Utilisation Of Translation Strategies In The FIRSt TEXT

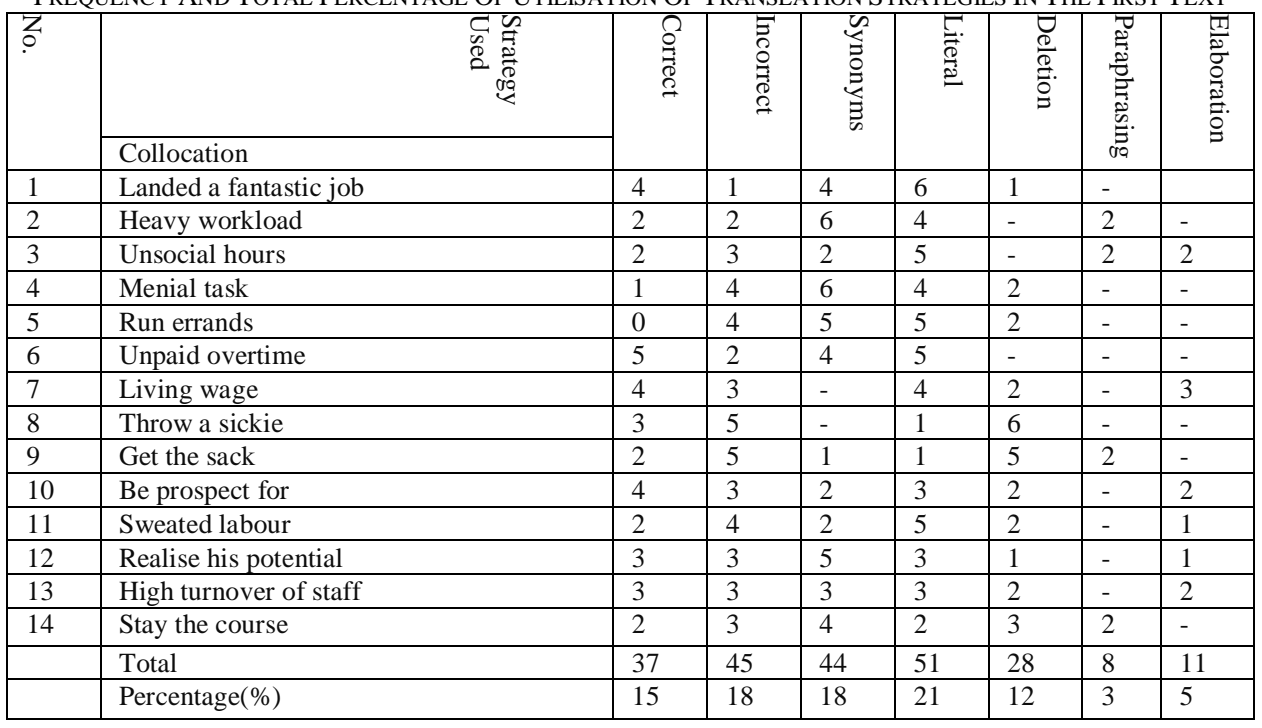

b. Translation Strategies Used in the Second Text.

Table 4 shows the percentages of the used translation strategies. Synonyms are the leading strategy used by $24.3 \%$ of the students followed by literal translation with $17.1 \%$, while $5 \%$ of the participants employ the strategy of deletion. Paraphrasing and elaboration are the least used strategies with rates of $2.1 \%$ and $4.3 \%$, respectively. 
TABLE IV.

FREQUENCY AND TOtal PERCENTAGe Of Utilisation

OF TRANSLATION STRATEGIES IN THE SECOND TEXT

\begin{tabular}{|c|c|c|c|c|c|c|c|}
\hline 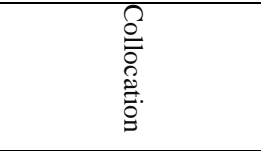 & $\begin{array}{l}\Omega \\
\stackrel{7}{2} \\
\stackrel{2}{2}\end{array}$ & $\begin{array}{l}\bar{\Xi} \\
0 \\
0 \\
ٍ ٍ]\end{array}$ & 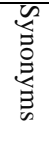 & $\begin{array}{l}\overrightarrow{\vec{D}} \\
\overrightarrow{0} \\
\end{array}$ & $\begin{array}{l}\frac{\overline{0}}{\infty} \\
\frac{0}{0} \\
\stackrel{0}{0}\end{array}$ & 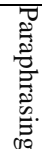 & 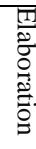 \\
\hline Sheer luxury & 2 & 2 & 3 & 3 & 1 & - & - \\
\hline Unrivalled service & 3 & & 3 & 2 & & - & - \\
\hline Exclusive restaurant & 4 & 1 & 3 & - & 1 & - & 2 \\
\hline Gracious living & 2 & 4 & 2 & 2 & - & 1 & - \\
\hline Grand style & 2 & 2 & 4 & 3 & - & & - \\
\hline Anti-ageing properties & 4 & 3 & 1 & 2 & - & 1 & - \\
\hline Clinically proven & 3 & 2 & 2 & 2 & 1 & 1 & - \\
\hline Banish wrinkles & 4 & 2 & 2 & 1 & 1 & - & 1 \\
\hline Luxury cream & & & & & & - & - \\
\hline Fine lines & 3 & 2 & 3 & 2 & 1 & - & - \\
\hline Flawless complexion & 3 & 3 & 3 & 2 & - & - & - \\
\hline Pile on pounds & 2 & 2 & 3 & 4 & - & - & - \\
\hline Tasty snack & 3 & 2 & 4 & & - & - & 2 \\
\hline Feel peckish & 2 & 4 & 1 & 1 & 2 & - & 1 \\
\hline Frequency & 37 & 29 & 34 & 24 & 7 & 3 & 6 \\
\hline Percentage(\%) & 26 & 21 & 24 & 17 & 5 & 2 & 4 \\
\hline
\end{tabular}

c. Translation Strategies Used in the Third Text.

Table 5 indicates that $26.8 \%$ is the percentage of the students resorting to the strategy of synonyms, while $22 \%$ uses literal translation. Paraphrasing is employed by $3.94 \%$ of students and deletion has a rate of $2.4 \%$. Only $0.8 \%$ of the students' responses show the use of elaboration strategy.

TABLE V.

FREQUENCY AND PERCENTAGE OF UTILISATION

OF TRANSLATION STRATEGIES IN THE THIRD TEXT

\begin{tabular}{|c|c|c|c|c|c|c|c|c|}
\hline Z & $\begin{array}{l}\text { Oे } \\
\overline{0} \\
\stackrel{0}{0}\end{array}$ & $\begin{array}{l}\Omega \\
\stackrel{8}{8} \\
\stackrel{\Omega}{8}\end{array}$ & 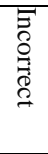 & $\begin{array}{l}\tilde{n} \\
\vdots \\
\vdots \\
\vdots \\
\vdots \\
\vdots\end{array}$ & $\begin{array}{l}\overrightarrow{\vec{d}} \\
\stackrel{\vec{D}}{0}\end{array}$ & $\begin{array}{l}\bar{O} \\
\frac{\pi}{0} \\
\stackrel{0}{0}\end{array}$ & 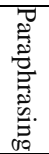 & $\begin{array}{l}\frac{\pi}{\tilde{\sigma}} \\
\tilde{\sigma} \\
\stackrel{0}{0} \\
\stackrel{\Xi}{0}\end{array}$ \\
\hline 1 & Pass law & 2 & 2 & 5 & 4 & - & - & - \\
\hline 2 & Introduce regulation & 4 & 3 & 3 & 2 & - & 1 & - \\
\hline 3 & Standardise procedure & 3 & 2 & 4 & 2 & 1 & 1 & - \\
\hline 4 & Adhere to standards & 4 & 2 & 4 & 2 & - & - & 1 \\
\hline 5 & Comply with law & 2 & 3 & 5 & 3 & - & - & - \\
\hline 6 & Have an obligation & 3 & 2 & 3 & 3 & 2 & - & - \\
\hline 7 & Carry out risk assessment & 4 & 2 & 2 & 3 & - & - & - \\
\hline 8 & Breach of the law & 4 & 3 & 2 & 3 & 1 & - & - \\
\hline 9 & Minimise danger & 3 & 2 & 4 & 4 & - & - & - \\
\hline \multirow[t]{3}{*}{10} & Satisfy the requirement & 4 & 3 & 2 & 2 & 1 & 1 & - \\
\hline & Total frequency & 33 & 24 & 34 & 28 & 5 & 3 & $\mathbf{1}$ \\
\hline & Percentage (\%) & 26 & 19 & 27 & 22 & 3.9 & 2.4 & 0.8 \\
\hline
\end{tabular}

The total percentage of the utilisation of translation strategies is calculated using the average of the percentages of the utilisation of the translation strategies in the three texts. Table 6 indicates that synonyms are the most employed strategy with a percentage of (23\%), followed by literal translation (20\%). Deletion is used at a rate of $6.88 \%$, while paraphrasing and elaboration are employed at a rate of $2.6 \%$ and $3.2 \%$, respectively, as shown in table 6 .

TABLE VI.

TOTAL PERCENTAGE OF UTILISATION OF

TRANSLATION STRATEGIES IN THE THREE TEXTS (\%)

\begin{tabular}{|c|c|c|c|c|c|c|c|}
\hline $\begin{array}{l}\vec{\otimes} \\
\underset{\square}{Z} \\
\stackrel{0}{0}\end{array}$ & 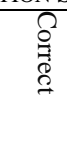 & 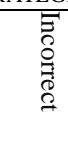 & 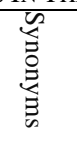 & 蛋 & 趸 & 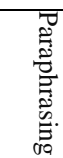 & 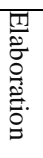 \\
\hline Text $1(\%)$ & 15.2 & 18.4 & 18.03 & 20.9 & 11.7 & 3.28 & 4.5 \\
\hline Text $2(\%)$ & 26.4 & 20.7 & 24.3 & 17.1 & 5 & 2.1 & 4.3 \\
\hline Text $3(\%)$ & 26 & 18.9 & 26.8 & 22 & 3.94 & 2.4 & 0.8 \\
\hline Total percentage $(\%)$ & 22.5 & 19.3 & 23 & 20 & 6.88 & 2.6 & 3.2 \\
\hline
\end{tabular}

2. Second: The Second Part of the Test: Translating Sentences

Table 7 shows the total frequency and percentages of the strategies employed in learners' responses. Synonym comes 
first $(21.5 \%)$, followed by literal translation (22.5\%). Deletion accounts for $4.3 \%$ of the strategies. Paraphrasing and elaboration are the least used strategies with rates of $3.8 \%$ and $3 \%$, respectively.

TABLE VII.

FREQUENCY AND TOTAL PERCENTAGE OF UTILISATION

\begin{tabular}{|c|c|c|c|c|c|c|c|c|}
\hline Z & 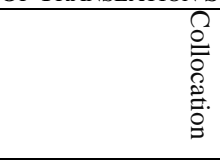 & $\begin{array}{l}\varrho \\
\varrho \\
\varrho\end{array}$ & 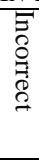 & $\begin{array}{l}\mathscr{\Xi} \\
\vdots \\
\Xi \\
\Xi\end{array}$ & 蛋 & 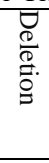 & 苛. & 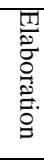 \\
\hline 1 & Brain drain & 5 & 11 & 7 & 9 & 5 & - & 3 \\
\hline 2 & Keep in touch & 10 & 9 & 9 & 7 & 3 & 2 & - \\
\hline 3 & Lame excuse & 7 & 8 & 9 & 11 & 3 & 2 & - \\
\hline 4 & Go astray & 11 & 10 & 8 & 9 & 1 & 1 & - \\
\hline 5 & Mood swings & 11 & 7 & 911 & 8 & - & 1 & 2 \\
\hline 6 & Heavy rain & 14 & 6 & 7 & 10 & - & 3 & - \\
\hline 7 & Make a decision & 11 & 7 & 10 & 9 & 2 & - & 1 \\
\hline 8 & Break the record & 10 & 9 & 7 & 10 & - & 2 & 2 \\
\hline 9 & Piece of advice & 12 & 5 & 6 & 9 & 2 & 4 & 2 \\
\hline 10 & Terribly sorry & 13 & 4 & 12 & 8 & 1 & - & 2 \\
\hline & Total frequency & 104 & 76 & 86 & 90 & 17 & 15 & 12 \\
\hline & Percentage (\%) & 26 & 19 & 21.5 & 22.5 & 4.3 & 3.8 & 3 \\
\hline
\end{tabular}

To determine the total percentage of the utilisation of translation strategies in the entire translation test, we calculate the average of the percentage of translating the three texts and translating the sentences. Table 8 shows that synonyms are the most frequently used strategy with a rate of $22.25 \%$. Literal translation comes second with $21.25 \%$ and deletion strategy accounts for $5.6 \%$ of the given responses. Paraphrasing and elaboration are the least frequently used strategies with rates of $3.2 \%$ and $3.1 \%$, respectively.

TABLE VIII.

Total Percentage OF Utilization Of TRANSLATION

STRATEGIES IN THE ENTIRE TRANSLATION TEST (\%)

\begin{tabular}{|c|c|c|c|c|c|c|c|c|}
\hline & 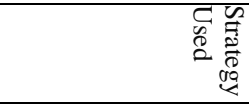 & \multirow[t]{2}{*}{$\begin{array}{l}\Omega \\
\stackrel{8}{0} \\
\stackrel{\Omega}{\varrho}\end{array}$} & \multirow[t]{2}{*}{ 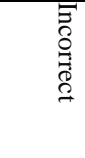 } & \multirow[t]{2}{*}{ 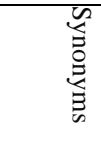 } & \multirow[t]{2}{*}{$\begin{array}{l}\overrightarrow{\overrightarrow{0}} \\
\overrightarrow{0}\end{array}$} & \multirow[t]{2}{*}{ 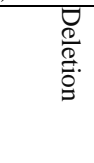 } & \multirow{2}{*}{ 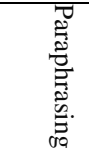 } & \multirow{2}{*}{ 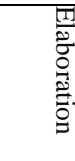 } \\
\hline & Type & & & & & & & \\
\hline 1. & Texts $(\%)$ & 22.5 & 19 & 23 & 20 & 6.9 & 2.6 & 3.2 \\
\hline \multirow[t]{2}{*}{2.} & Sentences $(\%)$ & 26 & 19 & 21.5 & 22.5 & 4.3 & 3.8 & 3 \\
\hline & Total $(\%)$ & 24 & 19 & 22 & 21.3 & 5.6 & 3.2 & 3.1 \\
\hline
\end{tabular}

\section{Relationship between EFL Learners' Familiarity with English Collocations and Strategies Used to Translate Them into Arabic}

To determine the relationship between Najran University EFL learners' familiarity with English collocations and the strategies they use to translate them into Arabic, Pearson correlation test is run between the results of the two tests. Results are shown in Table 9.

TABLE IX. CORRELATION OF FAMILIARITY WITH ENGLISH COLLOCATION AND STRATEGIES TO TRANSLATE INTO ARABIC

\begin{tabular}{|l|l|l|}
\hline \multicolumn{2}{|c|}{} & $\begin{array}{l}\text { Translation strategies } \\
\text { used }\end{array}$ \\
\hline \multirow{2}{*}{$\begin{array}{l}\text { Familiarity } \\
\text { collocations }\end{array}$} & Pearson Correlation & $0.734^{* *}$ \\
\cline { 2 - 3 } & Sig. (2-tailed) & 0.000 \\
\cline { 2 - 3 } & $\mathrm{N}$ & 40 \\
\hline
\end{tabular}

The results indicate that a positive correlation exists between the EFL learners' familiarity with English collocations and their familiarity with strategies to translate them into Arabic $(\mathrm{R}=0.734, p<0)$. As the learners' familiarity with English collocations increases, their ability to translate English collocations into Arabic and to use appropriate translation strategies shows a significant increase.

\section{Reasons behind Students' Difficulties While Translating Collocations into Arabic}

To determine the most common reasons behind the students' difficulties while translating collocations, we prepared and distributed a questionnaire citing some of the common reasons behind the difficulty of translating collocations. Frequencies, percentages and means of the responses are calculated to determine the most common causes of difficulty and to find which of these causes constitute more difficulty than others. Results of the questionnaire are shown in the table below. 
TABLE X.

DESCRIPTIVE STATISTICS OF QUESTIONNAIRE ITEMS

\begin{tabular}{|c|c|c|c|c|c|c|c|c|}
\hline Item & 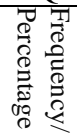 & 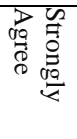 & $\underset{\substack{10 \\
8}}{\stackrel{8}{8}}$ & 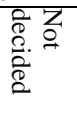 & 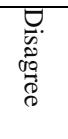 & 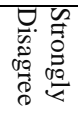 & $\begin{array}{l}3 \\
\stackrel{8}{9}\end{array}$ & $\mathscr{\theta}$ \\
\hline \multirow{2}{*}{ 1. I am aware of the processes and methods of translation. } & $\mathrm{F}$ & 9 & 13 & 4 & 7 & 7 & \multirow{2}{*}{3.25} & \multirow{2}{*}{0.89} \\
\hline & $\%$ & 22.5 & 32.5 & 10 & 17.5 & 17.5 & & \\
\hline \multirow{2}{*}{ 2. I am fully aware of collocations in English. } & $\mathrm{F}$ & 8 & 13 & 3 & 8 & 8 & \multirow{2}{*}{3.12} & \multirow{2}{*}{0.84} \\
\hline & $\%$ & 20 & 32.5 & 7.5 & 20 & 20 & & \\
\hline \multirow{2}{*}{ 3. I am fully aware of collocations in Arabic. } & $\mathrm{F}$ & 6 & 10 & 3 & 9 & 12 & \multirow{2}{*}{2.72} & \multirow{2}{*}{0.47} \\
\hline & $\%$ & 15 & 25 & 7.5 & 22.5 & 20 & & \\
\hline \multirow{2}{*}{$\begin{array}{l}\text { 4. I have taken some practice in collocations in my BA } \\
\text { English programme. }\end{array}$} & $\mathrm{F}$ & 6 & 8 & 4 & 9 & 13 & \multirow{2}{*}{2.62} & \multirow{2}{*}{0.58} \\
\hline & $\%$ & 17.5 & 20 & 10 & 32.5 & 20 & & \\
\hline \multirow{2}{*}{$\begin{array}{l}\text { 5. I have practised translation of collocations in my translation } \\
\text { courses. }\end{array}$} & $\mathrm{F}$ & 8 & 5 & 4 & 10 & 13 & \multirow{2}{*}{2.62} & \multirow{2}{*}{0.53} \\
\hline & $\%$ & 20 & 12.5 & 10 & 25 & 32.5 & & \\
\hline \multirow{2}{*}{$\begin{array}{l}\text { 6. I am aware of the kinds of texts given for translation } \\
\text { practice. }\end{array}$} & $\mathrm{F}$ & 6 & 8 & 3 & 11 & 12 & \multirow{2}{*}{2.62} & \multirow{2}{*}{0.60} \\
\hline & $\%$ & 15 & 20 & 7.5 & 27.5 & 30 & & \\
\hline \multirow{2}{*}{$\begin{array}{l}\text { 7. I have difficulty in translating collocations from Arabic to } \\
\text { English. }\end{array}$} & $\mathrm{F}$ & 12 & 11 & 4 & 6 & 7 & \multirow{2}{*}{3.37} & \multirow{2}{*}{0.63} \\
\hline & $\%$ & 30 & 27.5 & 10 & 15 & 17.5 & & \\
\hline \multirow{2}{*}{$\begin{array}{l}\text { 8. I have difficulty in translating collocations from English to } \\
\text { Arabic. }\end{array}$} & $\mathrm{F}$ & 13 & 10 & 2 & 9 & 6 & \multirow{2}{*}{3.37} & \multirow{2}{*}{0.71} \\
\hline & $\%$ & 32.5 & 25 & 5 & 22.5 & 15 & & \\
\hline \multirow{2}{*}{$\begin{array}{l}\text { 9. I have difficulty in translating idiomatic expressions in } \\
\text { general. }\end{array}$} & $\mathrm{F}$ & 14 & 12 & 2 & 6 & 6 & \multirow{2}{*}{3.55} & \multirow{2}{*}{0.74} \\
\hline & $\%$ & 35 & 30 & 5 & 15 & 15 & & \\
\hline \multirow{2}{*}{$\begin{array}{l}\text { 10. I cannot translate collocations because I do not have much } \\
\text { exposure to the English culture. }\end{array}$} & $\mathrm{F}$ & 13 & 14 & 2 & 6 & 5 & \multirow{2}{*}{3.60} & \multirow{2}{*}{0.84} \\
\hline & $\%$ & 32.5 & 35 & 5 & 15 & 12.5 & & \\
\hline 11. I have difficulty in translating collocations because I & $\mathrm{F}$ & 10 & 11 & 3 & 9 & 7 & 32 & 078 \\
\hline cannot find the accurate equivalent of the words. & $\%$ & 25 & 27.5 & 7.5 & 23.5 & 17.5 & 3.2 & 0.18 \\
\hline 12. I understand the functions of English collocations within & $\mathrm{F}$ & 8 & 7 & 2 & 13 & 10 & & 065 \\
\hline the vocabulary usage. & $\%$ & 20 & 17.5 & 5 & 32.5 & 25 & 2.75 & 0.65 \\
\hline 13. The difference between the source language and the target & $\mathrm{F}$ & 11 & 14 & 3 & 6 & 6 & 345 & 067 \\
\hline language systems causes difficulty in translating collocations. & $\%$ & 27.5 & 35 & 7.5 & 15 & 15 & 3.45 & $0.6 /$ \\
\hline 14. The metaphorical use of collocations causes difficulty for & $\mathrm{F}$ & 10 & 11 & 2 & 9 & 8 & 315 & 074 \\
\hline me to translate them. & $\%$ & 25 & 27.5 & 5 & 22.5 & 20 & 3.15 & 0.74 \\
\hline
\end{tabular}

Table 10 shows that $55 \%$ of the participants agree with item 1, with a mean of 3.25 and standard deviation of 0.89 . Responses to item 2 indicate that $40 \%$ of the participants agree on being fully aware of collocations in Arabic and $42.5 \%$ disagree on it. With a mean of 3.12 and standard deviation of 0.84 , responses to item 3 reveal that $52.5 \%$ of the participants agree on being aware of collocations in English while 40.5\%disagree and admit to having a low level of collocation knowledge. Responses to item 4with a mean of 2.62 and standard deviation 0.53 indicate that only $37.5 \%$ of the participants agree to have some practice in collocations in the BA English programme, whereas $52.5 \%$ of the participants disagree about having practice in collocations in the English programme and $10 \%$ are undecided.

With a mean of 2.62 and standard deviation of 0.60 , response results to item 6 indicate that only $35 \%$ of the participants approve of being aware of the types of texts given for translation practice, while $57.5 \%$ disapprove of being aware of the types of texts given for translation practice. With a mean of 2.62 and standard deviation of 0.58 , response results to item 5 show that a high percentage $(57.5 \%)$ of the participants disagree on having practice in the translation of collocations in translation courses, while only $32.5 \%$ agree on having practice in the translation collocations in translation courses. Results of items 7 and 8 show that more than half of the participants agree on experiencing difficulty in translating collocations from Arabic into English (mean [3.37], standard deviation [0.63] and percentage (57.5\%]). Respondents also agree on facing difficulty when translating collocations from English into Arabic (mean [3.3], standard deviation [0.71] and percentage [57.5\%]).

The results of responses to item 9 indicate that a high percentage $(65 \%)$ of the participants agree on facing difficulty to translate idiomatic language in general. Responses to item 10 show that $67.5 \%$ of the participants view the lack of exposure to English culture as a leading cause of their difficulty in translating collocations. Responses to item 11 reveal that $52.5 \%$ of the participants agree on having difficulty in translating collocations because of the difficulty of finding the accurate equivalent for the words, with a mean of 3.2 and standard deviation of 0.78 .Furthermore, results of item 12 indicate that only $37.5 \%$ of the participants agree on understanding the functions of English collocations within the vocabulary usage, with a mean of 2.75 and standard deviation of 0.65 , whereas $57.5 \%$ disagree on understanding the function of collocations. Item 13('the difference between the source language and target language systems causes difficulty in translating collocations') acquires a high percentage (62.5\%) of participants' agreement. Finally, responses to item 14 show that $52.5 \%$ of the participants agree on attributing some of the difficulty of translating collocations to the metaphoric use of collocations, with a mean of 3.15 and a standard deviation of 0.74 .

\section{DISCUSSION OF FINDINGS}

\section{A. Learners' Familiarity with English Collocations}


The first question of the study is related to the extent to which Najran University EFL learners are familiar with English collocations. A descriptive analysis of the students' results in the collocation test by means of one sample t-test is conducted to answer the question (see Table1). The results show that the mean of the students' results is 21 out of 50 , which is below $50 \%$ of the total mark, thereby indicating that the level of the learners' collocation knowledge is poor and beneath what is expected from Level 6 university students majoring in English.

In addition, the results of the t-test show no significant difference between the mean degree of the students in collocations and the supposed test value, thus supporting the alternative hypothesis of the study which is 'EFL learners at Najran University are familiar with English collocations'. Although the EFL learners are familiar with the notion of English collocations, the level of their familiarity is unsatisfactory as an expectation from sixth-level university learners specialising in the English language. This low level of familiarity is consistent with the results of many previous studies, including Zughoul and Abdul-Fattah (2003), Abdullah (2010), Al-Sakran (2011), Shammas (2013) and Hadi (2014), which have revealed that the learners' knowledge of collocations is disappointing and stated that further emphasis on collocations is needed in teaching vocabulary.

\section{B. Learners' Familiarity with Translation Strategies When Rendering English Collocations into Arabic}

To answer the second question of the study, which refers to Najran University EFL learners' familiarity with translation strategies in rendering English collocations into Arabic, a descriptive analysis of the mean of the students' marks in the translation test is run using one sample t-test (see Table 2). The results show that that the mean of the students' mark is 10.96 (out of 20), indicating that the students' level of translation strategies when rendering collocations into Arabic is inadequate and below the expected level. Furthermore, the translation strategies they use do not fulfil the purpose of using them in the first place and do not truly solve the translation problems encountered. Thus, the students do not resort to effective translation strategies in the case of translating English collocations.

The learners' difficulty with translating collocations and using appropriate translation strategies for this purpose is consistent with the results of many studies that have investigated the same subject. According to Jabak, Abdullah and Mustafa (2016), most Arab university learners face difficulty in translating collocations because of their heavy utilisation of literal translation and their insufficient knowledge of both Arabic and English languages. The result is also in accordance with the findings of Koç (2006) that 'most strategies used by the EFL learners are not helpful. Nevertheless, they provide a holistic picture of the processes that students undergo while generating the target collocations and can be helpful for teachers of EFL to know' (p.31). However, Shraideh and Mahadin (2015) have found that MA students have a good knowledge of translating collocations using the appropriate translation strategies unlike BA students who show lack of knowledge of translating collocations.

The results of the t-test also show that no significant difference exists between the mean degree of the students in the translation test and the supposed test mean, thereby supporting the alternative hypothesis that 'EFL learners at Najran University are aware of translation strategies in rendering English collocations into Arabic'. Nevertheless, the level of their awareness of translation strategies is inadequate and disappointing particularly as the students are expected to be advanced learners of English and the used collocations in the test are familiar and commonly used in the English language.

An analysis of the strategies used in rendering the given collocations into Arabic also show that due to the learners' inadequate knowledge of collocations, they resort to five distinctive translation strategies: nearest synonyms, literal translation, deletion, elaboration and paraphrasing (see Table 8). The following are brief descriptions of these strategies and some samples that are obtained from the participants' responses:

Near synonyms: This strategy comes as the most frequently used strategy, accounting for $22.25 \%$ of the responses. The learners' heavy reliance on using synonyms as a strategy can be attributed to their inadequate knowledge of collocations, which prevents the free replacement of words by their synonyms or near synonyms. This fact is stated clearly by Baker (1992) as follows: 'words which we might think of as synonyms or near-synonyms will often have quite different sets of collocates'(p. 47). Some examples of rendering of collocations using this strategy include the translation of 'pass law' as يمرر القانون'Lame excuses 'is translated by some participants into أعذار غير مقبولة'Sand

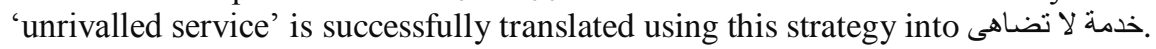

Literal translation: This strategy comes second as it is used by $21.25 \%$ of the students and only with a slight difference from synonyms. When the learners are hindered by their inefficient collocational knowledge, they resort to literal translation of the components of collocations, i.e., word-for-word translation as the result of the learners' negligence of the restricted nature of collocations and the fact that no one-to-one correspondence exists between the source and the target language. 'By employing literal translation to render collocations that carry certain semantic messages, the message implied is often distorted leading to more ambiguity' (Dweik and Abu Shakra, 2010, p.29). Examples of given translations using this strategy include the translation of 'brain drain' as تصريف الدماغ. Similarly, some participants have translated 'run errands' literally into يشغل المهمات and 'lame excuses' is translated by some participants into أعذار عرجاء.

Deletion: This strategy accounts for $5.6 \%$ of the given responses by the participants who use it. When employing this strategy, learners 'tend to abandon large units of the message in the SL as a result of incomprehensibility of semantic units' (Dweik and Abu Shakra, 2010, p. 20). Some examples of renditions using deletion include the translation of 'menial tasks' into القيام بالمهام and 'sheer luxury' into الرخاء. 
Elaboration: Based on the results, this strategy is employed only by a small percentage (3.2\%) of the participants. Sometimes, when the translator faces difficulty in finding the direct equivalent of a given collocation, he/she may

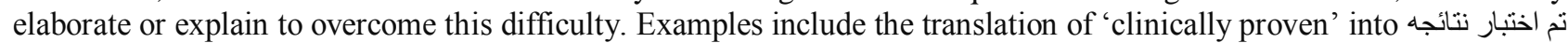

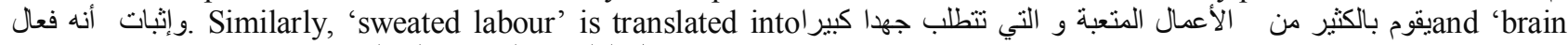
drain’ is translated into انتقال العلماءو المفكرين إلى الخارج '

Paraphrasing: This is the least employed strategy with only $3 \%$ of the given responses. To overcome their inefficient knowledge of collocations, the participants paraphrase the meaning of collocations using their own words, but this strategy is not highly recommended in translating collocations because it does not bring the source text effects to the reader' (Sharidah and Mahadain,2015, p.373). Examples such as 'realise his potential' is translated by some participants into حتى يمكنه تحقيق التقدم في وظيفتا. Similarly, 'mood swings 'is translated into سوء المزاج.

Some of the collocations under question in the translation test constitute more difficulty for the students than the other collocations such as 'menial tasks', 'run errands', 'pile on pounds', 'feel peckish', 'brain drain' and 'throw a sickie'. These collocations received a fewer number of correct answers because of the following factors:1) the collocations are less common to the participants than the other items, 2) the collocations are less congruent with their mother tongue and 3) the translation strategies which the participants heavily relied on such as synonyms and literal translation do not help achieve the meaning of these items. The items which have received more correct answers include 'unpaid overtime', 'banish wrinkles', 'anti-ageing properties', 'breach the law', 'adhere to standards', 'keep in touch', 'heavy rain' and 'terribly sorry'. These items seem easier because they are more common to the participants. These collocations are also more congruent with Arabic as 'the first language interferes positively with congruent collocations but it does not help with the non-congruent ones' (Migdad, 2012, p.88). In the case of congruent collocations, the heavily used translation strategies (synonyms and literal translation) help in arriving at the correct meaning of these items.

\section{Correlation between Learners' Familiarity with English Collocations and Strategies Used in Rendering Collocations into Arabic}

To answer the third question, which refers to the relation between Najran University EFL learners' familiarity with English collocations and the strategies they use to translate them into Arabic, the Pearson correlation test is used. The results of this test show a significant correlation between the learners' familiarity with English collocations and their ability to translate collocations and consequently use the proper strategies that yield acceptable translations (see Table 9). This result indicates that the more the learner is familiar with collocations, the better is his/her use of strategies when translating them into Arabic. The learners' knowledge of English collocations will reflect on his/her ability to translate and employ the appropriate translation strategies when translating them into Arabic. These results are in parallel with the findings of Noor and Adubaib (2011) who asserted that the teaching of collocational strategies may not help improve the production of acceptable collocations, whereas the explicit teaching of collocations is more effective in improving the production of acceptable collocations. This view is in accordance with the findings of Bialystok (1990) who believes that 'the more language the learner knows, the more possibilities exist for the system to be flexible and adjust itself to meet the demands of the learner. What one must teach students of a language is not strategy, but language' (p. 147).

\section{Reasons behind Students' Difficulties While Translating Collocations}

To investigate the learners' difficulties while translating collocations, a questionnaire on the students' difficulties in translating collocations was developed and distributed amongst the same participants who had answered the collocation and translation tests. Frequencies, percentage and means of responses are calculated to find out the most common causes of the students' difficulty in translating English collocations into Arabic (see Table 4-10). The reasons presented in the questionnaire can be categorised into two dimensions. One of them is related to the students' background and the kind of education they have received on collocations and translation. The second dimension is related to the students' perspective of the difficulty in translating Arabic and English collocations and some possible reasons which are related to the inherent properties of collocations. The results show that the learners agree to most of the given items and see them as reasons behind the difficulty in translating collocations. The items of the second dimension are observed to constitute greater difficulty faced by the students than the items of the first dimension.

The first and the second items, 'I am aware of the process and methods of translation' and 'I am fully aware of collocations in English, 'have received 55\% and 52.5\% of the students' agreement, respectively, thereby indicating that the learners do not consider their familiarity with translation and its process and their familiarity with collocations as causes of the difficulty in translating collocations because 35\% and $40 \%$ have disagreed with these two items, respectively. The results of these items support the results of collocations and translation test in this study, but the level of the students' familiarity is unsatisfactory as indicated by this study and many previous studies in this domain. The results of the third item, 'I am fully aware of collocations in Arabic, 'indicates that the participants are less familiar with Arabic collocations than with English collocations because the former are rarely discussed in the general curriculum and is taken for granted when teaching native speakers of a given language. The students also take some of the responsibility for their insufficient knowledge of Arabic Collocations. The learners' limited knowledge of Arabic 
collocations contribute to their low level in translating collocations because translation is a process that entails mastery of both the source and target languages.

The results of item 4 show that $52.5 \%$ of the students do not agree on having enough practice in collocations in the BA programme, whereas students' responses to item 5 show that a high percentage $(57.5 \%)$ do not agree on having practice in translating collocations. Results of item 6 reveal that $57.5 \%$ of the students are unaware of the type of texts used in translation practice. The results of items 4,5 and 6 indicate that the students agree on attributing some of the causes of their difficulty in translating collocations to the curriculum and instruction they have received.

Items 7 and 8, which are about facing difficulty in translating collocations from Arabic into English and vice versa, both have a mean of 3.37 and rates of $56 \%$ and $65 \%$, respectively, which show the students' agreement on facing difficulty in translating collocations. Item 9, 'I experience difficulty in translating idiomatic language in general, 'which has a mean of 3.55 and agreement rate of $65 \%$, is the second cause of learners' difficulty when translating collocations.

The results of responses to item 10, 'I cannot translate collocations because I do not have much exposure to English culture,' show that this item, with a percentage of $67.5 \%$ and a mean of 3.6 , has the highest percentage of agreement as a cause of difficulty in translating collocations. Item 13, "The difference between the source language and target language systems causes difficulty in translating collocations, 'is the third most common cause of the difficulty with a mean of 3.45 and agreement rate of $62.5 \%$. The first three common reasons for the learners' difficulty in translating are the properties of collocations and source and target languages. The importance of the culture associated with the language is emphasised by many studies on the translation of collocations including that of Nofal (2012) who considers the cultural awareness of the source and target languages as a prerequisite for a successful translation. The difficulty in translating idiomatic language has been confirmed by many researchers including Juma'a (2014) and Ali and AlRushaidi(2016). The differences between the linguistic systems of the source and the target language as a cause of the difficulty in translating collocations is confirmed by Sarikas (2006).

Furthermore, results of items 11 and 14 reveal that a large group of students view the lack of equivalents of some collocations and their metaphorical use as causes of the difficulty when translating collocations (rate of agreement is $52.5 \%$ for both items). These results are in accordance with many studies, including Zughoul (1991) and Zughoul and Abdul-Fattah (2013), which consider the lack of equivalence as a cause of the difficulty in translating collocations, thereby explaining why most of the students resort to the strategies of synonymity and literal translation when translating collocations. Shraidah and Mahadin (2015) show that synonym and literal translation are the most frequently used strategies by MA and BA students when translating collocations.

\section{CONCLUSION}

Although the importance of collocations has been recognised by scholars in the last two decades, EFL learners' knowledge remains inadequate as indicated by the results of many previous studies in this domain. The present study is in accordance with many previous studies in the sense that the findings reveal a low level of EFL learners' collocational knowledge and a low level of familiarity with strategies when rendering English collocations into Arabic as the learners relied heavily on strategies, such as synonyms and literal translation, which yield unacceptable and odd collocations.

In addition, this study reveals a significant correlation between the learners' familiarity with collocations and with translation strategies when translating English collocations into Arabic. These findings suggest that the learners' knowledge of collocations is reflected in their ability to translate them, thus indicating that expanding the EFL learners' repertoire of collocations is more effective than focusing on teaching strategies for translating collocations. Furthermore, the present study attributes the difficulties of learning and translating to several factors. Some of them are related to the inherent properties of collocations, others are related to the curriculum and teaching material design and the rest are attributed to language teachers and the learners themselves. Consequently, collaborative and comprehensive work is necessary in the future. All the parties involved in the learning and teaching process should work together to overcome the difficulties faced by learners in comprehending, producing and translating collocations.

\section{REFERENCES}

[1] Abdullah, E.M. (2014). Investigating collocational knowledge: A case study of English majors at college of languages, SUST (Master's thesis). Retrieved from www.repository.sustech.edu/handle/123456789/9571 (accessed 6/1/2019).

[2] Ali, H. I. H., Al-Rushaidi, S., \& Mohammed, S. (2016). Translating Idiomatic Expressions from English into Arabic: Difficulties and Strategies. Arab World English Journal (AWEJ), 7 (4),187-201.Retrived https://dx.doi.org/10.24093/awej/vol7no4.13 (accessed 1/8/2018).

[3] Al-Sakran, R.A. (2011). The productive and receptive knowledge of collocations by advanced Arabic speaking ESL/EFL learners (Master's thesis). https://dspace.library.colostate.edu/bitstream/.../Alsakran_colostate_0053N_10485.pdf(accessed 30/7/2018 ).

[4] Baker, M. (1992). In other words: A course book on translation. London and New York: Routledge.

[5] Bahns, J. (1993). Lexical collocations: A contrastive view. ELT Journal, 47(1), 56-63. Retrieved from https://doi.org/10.1093/elt/47.1.56 (accessed 12/7/2018).

[6] Bialystok, E. (1990). Communication strategies: A psychological analysis of second language use. Retrieved from https://cloudfront.escholarship.org/dist/prd/content/qt0nm485t0/qt0nm485t0.pdf (accessed 29/11/2018). 
[7] Brashi, A S (2005). Arabic collocations: Implication for translation (Doctoral dissertation). Retrieved from www.researchdirect.uws.edu.au/islandora/object/uws\%3A2509 (accessed 3/2/2019).

[8] Dweik, B. S., \& Abu Shakra, M. M. (2011). Problems in translating collocations in religious texts from Arabic into English. Linguistics Journal, 5(1) 320-356. Retrieved from www.files.eric.ed.gov/fulltext/ED510365.pdf (accessed 24/5/2018).

[9] Farghal, M., \& Obiedat, H. (1995). Collocations: A neglected variable in EFL. IRAL - International Review of Applied Linguistics in Language Teaching, 33(4), 315-332. Retrieved from https://doi.org/10.1515/iral.1995.33.4.315 (accessed 12/2/2018).

[10] Farrokh, P. (2012). Raising awareness of collocation in ESL/EFL classrooms. Journal of Studies in Education, 2(3), 55-74. www.doi:10.5296/jse.v2i3.1615 (accessed 4/2/2019).

[11] Gazala, H (2007). A comprehensive English-Arabic dictionary of accuracy of word combination and usage. Beirut: Dar ALElm Lil Malayin.

[12] Gyllstad, H. (2007). Testing English collocation: Developing receptive tests for use with advanced Swedish learners (Doctoral dissertation). Retrieved from https://lup.lub.lu.se/search/ws/files/5893676/2172422.pdf (accessed 19/4/2018).

[13] Hadi, S. A.K. (2014). Iraqi EFL learners' use of English lexical collocations. The Journal of Babylon University, 22 (3), 566579. Retrieved from https://www.iasj.net (accessed 25/8/2018).

[14] Hatim, B., \& Mason, I. (1997). Translator as communicator. London: Routledge.

[15] Hill, J. (2000). Revising priorities: From grammatical failure to collocational success. In M. Lewis (Ed.), Teaching collocation: Further developments in the lexical approach. Retrieved from https://kupdf.net/download/michael-lewis-ed-(accessed 22/6/2018).

[16] Huang, L.S (2001). Knowledge of English Collocations: An Analysis of Taiwanese EFL Learners. In Luke, C. and B. Rubrecht (Eds). Texas Papers in Foreign Language Education: Selected Proceedings from the Texas Foreign Language Education Conference (pp. 2-20). Retrieved from http://files.eric.ed.gov/fulltext/ED465288.pdf (accessed 11/4/2018).

[17] Husni, R \&Newman, D. L. (2015). Arabic-English-Arabic translation: Issues and strategies. Retrieved from https://www.routledge.com/Arabic-English-Arabic-Translation-Issues-and-Strategies (accessed 4/6/2018).

[18] Jabak, O. O., Abdullah, S. N. S., \& Mustapha, N. F. (2016). The Difficulty of translating collocations from Arabic into English encountered by a sample of Arab students. Jurnal Sultan Alauddin Sulaiman Shah 3(1), 266-275. Retrieved from www.journal.kuis.edu.my/jsass/images/files4b/4_025-Omar.pdf (accessed 5/6/2018 ).

[19] Juma'a, O.S. (2014). Translating idiomatic expressions from English into Arabic (Master Thesis). Retrieved from www.meu.edu.jo (accessed 26/9/2018).

[20] Koç, G. (2006). Developing collocational awareness (Master Thesis). Retrieved from www.thesis.bilkent.edu.tr/0003109.pdf (accessed 17/5/2018).

[21] Lewis, M. (1997). Implementing the Lexical Approach .Retrieved from https://www.researchgate.net/publication/31750531_Implementing_the_Lexical_Approach_Putting_Theory_into_Practice_M_ Lewis_colaboracion_de_C_Gough_et_al (accessed 1/12/2018).

[22] Lörscher, W. (2005). The translation process: Methods and problems of its investigation. Meta, 50(2), 597-608. Retrieved from http://www.erudit.org/revue/meta/2005/v50/n2/011003ar.pdf (accessed 16/1/2019).

[23] McCarthy, M. (1990). Vocabulary. Oxford: Oxford University Press. Retrieved from https://trove.nla.gov.au/version/23336217 (accessed 22/4/2018).

[24] Migdad, A. A (2012). The Role of mother tongue in reception and production of collocations by English majors at the Palestinian Universities (Master's thesis). Retrieved from https://www.researchgate.net/publication/301945675_English_language_students'_productive_and_receptive_knowledge_of_c ollocations (accessed 3/1/2019).

[25] Nation, I. (2001). Learning vocabulary in another language. Cambridge: Cambridge University Press. www.doi:10.1017/CBO9781139524759 (accessed 4/6/2018).

[26] Nesselhauf, N. (2003). The Use of collocations by advanced learners of English and some implications for teaching. Applied Linguistics, 24(2), 223-242. https://doi.org/10.1093/applin/24.2.223 (accessed 5/8/2018).

[27] Nesselhauf, N. (2004). Collocations in a learner corpus. Amsterdam: John Benjamins.

[28] Newmark, P. (1988). A textbook of translation https://doi.org/10.1017/CBO9781107415324.004 (accessed 11/1/2019)

[29] Nofal, K. H. (2012). Collocations in English and Arabic: A comparative study. English language and literature studies, 2(3), 75. www.doi:10.5539/ells. v2n3p75 (accessed 12/2/2018).

[30] Noor, H and Adubaib. (2011). Strategies used in producing English lexical collocations by Saudi EFL learners. Paper presented at 1 st International Conference on Foreign Language Teaching and Applied Linguistics. Sarajevo. Retrieved from https://www.researchgate.net/267422841 (accessed 7/9/2018).

[31] O'Dell, F., \& McCarthy, M. (2008). English collocations in use: Advanced. Cambridge: Cambridge University Press.

[32] Rabeh, F (2009). Problems in translating collocations: The case of master students of applied languages (Master's thesis). Retrieved from https://bu.umc.edu.dz/theses/anglais/FAN1152.pdf (accessed 14/8/2018).

[33] Sarikas, O. G. F. (2006). Problems in translating collocations. Elektronik Sosyal Bilimler Dergisi, 17(17),33-40.Retrieved from http://dergipark.gov.tr/download/article-file/69901 (accessed3 /6/2018.

[34] Shammas, N.A. (2013).Collocation in English: Comprehension and use by MA students at Arab universities. International Journal of Humanities and Social Science, 3(5), 107-122.

[35] Shraideh, K.W., \& Mahadin, R. S. (2015). Difficulties and strategies in translating collocations in BBC political texts. Arab World English Journal, 8 (3), 320- 356. doi: https://dx.doi.org/10.24093/awej/vol6no3.21 (accessed 14/4/2018).

[36] Vinay, J.P., \& Darbelnet, J. (1995). Stylistiquecomparée du franchais et de l'anglais: Méthode de Traduction (Comparative stylistics of French and English: A methodology for Translation). (Sager, J.C., \& Hamel, M.J. Trans). Retrieved from https://www.researchgate.net/.../307725092_ (accessed 1/1/2018).

[37] Wilkins, D. A. (1972). Linguistics in language teaching. Retrieved from https://catalogue.nla.gov.au/Record/1233140 (accessed 2/3/2018). 
[38] Zughoul, M. R. (1991). Lexical choice: Towards writing problematic word lists. International Review of Applied Linguistics, 29(1), 45-60.

[39] Zughoul, M. R., \& Abdul-Fattah, H. (2003). Translational collocational strategies of Arab learners of English: A study in lexical semantics. Babel, 49(1), 59-81.

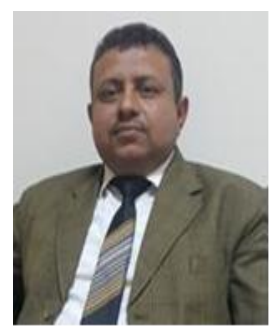

Hussein Ali Habtoor is an associate professor of applied linguistics at the University of Aden, YEMEN. He worked at King Saud University, Riyadh from 2007 till 2009. He is currently in a sabbatical at the University of Najran in KSA as an associate professor of applied linguistics. His interests include Second Language Acquisition, Reading in Second Language Research, Translation Studies and Critical Discourse Analysis. He is an editorial member of a number of international journals and he is currently supervising a number of M.A. research students at the programme of Applied Linguistics at Najran University

Raisah Hamad Al-Swaidan is a lecturer at the Department of English at the University of Najran, KSA. She did her M.A. research in Applied Linguistics at the University of Najran. Her interests include Second language Acquisition Research and Vocabulary Acquisition. 